\title{
Dark-Field Scattering and Local SERS Mapping from Plasmonic Aluminum Bowtie Antenna Array
}

\author{
Thang Duy Dao ${ }^{1,2}$, Chung Vu Hoang ${ }^{3,4, *}$, Natsuki Nishio ${ }^{5}$, Naoki Yamamoto ${ }^{5}$, Akihiko Ohi ${ }^{1}$, \\ Toshihide Nabatame ${ }^{1}$, Masakazu Aono ${ }^{1}$ and Tadaaki Nagao ${ }^{1,6, *(D)}$ \\ 1 International Center for Materials Nanoarchitectonics (MANA), National Institute for Materials \\ Science (NIMS), 1-1 Namiki, Tsukuba 305-0044, Japan \\ 2 Graduate School of Materials Science, Nara Institute of Science and Technology, 8916-5 Takayama, Ikoma, \\ Nara 630-0192, Japan \\ 3 Institute of Materials Science (IMS), Vietnam Academy of Science and Technology (VAST), \\ 18 Hoang Quoc Viet street, Hanoi 100000, Vietnam \\ 4 Institute of Theoretical and Applied Research (ITAR), Duy Tan University, 1 Phung Chi Kien Street, \\ Hanoi 100000, Vietnam \\ 5 Physics Department, Tokyo Institute of Technology, Meguro-ku, Tokyo 152-8551, Japan \\ 6 Department of Condensed Matter Physics, Graduate School of Science, Hokkaido University, \\ Kita-10 Nishi-8 Kita-ku, Sapporo 060-0810, Japan \\ * Correspondence: chunghv@ims.vast.ac.vn (C.V.H.); nagao.tadaaki@nims.go.jp (T.N.); \\ Tel.: +84-24-375-64129 (C.V.H.); +81-29-860-4709 (T.N.)
}

Received: 22 April 2019; Accepted: 11 July 2019; Published: 13 July 2019

\begin{abstract}
On the search for the practical plasmonic materials beyond noble metals, aluminum has been emerging as a favorable candidate as it is abundant and offers the possibility of tailoring the plasmonic resonance spanning from ultra-violet to the infrared range. In this letter, in combination with the numerical electromagnetic simulations, we experimentally study the dark-field scattering spectral mapping of plasmonic resonance from the free-standing Al bowtie antenna arrays and correlate their strong nearfield enhancement with the sensing capability by means of surface-enhanced Raman spectroscopy. The spatial matching of plasmonic and Raman mapping puts another step to realize a very promising application of free-standing Al bowtie antennas for plasmonic sensing.
\end{abstract}

Keywords: aluminum; plasmonics; dark-field scattering; SERS; bow-tie antenna

\section{Introduction}

Alternative plasmonic materials beyond gold $(\mathrm{Au})$ and silver $(\mathrm{Ag})$, including transition metal nitrides and metal carbides [1-4], heavily-doped semiconductors [5-9], as well as graphene [10-15], have been widely investigated recently owing to their controllability of optical properties via chemical or physical doping processes. Being the third most abundant element on earth, after silicon and oxygen, aluminum ( $\mathrm{Al}$ ) has also been used widely in industry. In the past few years, aluminum have attracted tremendous interest in the field of plasmonics as it is a promising alternative replacement for noble plasmonic metals [16-20]. Having an ultrathin native oxide $\mathrm{Al}_{2} \mathrm{O}_{3}$ layer $(2 \mathrm{~nm}-4 \mathrm{~nm}), \mathrm{Al}$ emerges as a favorable material in the field of plasmonic sensing with the detection mechanism mainly based on the electromagnetic field enhancement rather than the charge transfer effect $[16,17,21,22]$. Compared to $\mathrm{Au}$ and $\mathrm{Ag}$ whose interband transitions are at $\sim 2.3 \mathrm{eV}$ and $\sim 3.9 \mathrm{eV}$ [23], respectively; $\mathrm{Al}$ has a lower interband transition energy of about $\sim 1.5 \mathrm{eV}$. Aluminum displays a plasma energy of $15.3 \mathrm{eV}$ thatis higher than that of $\mathrm{Au}$ and $\mathrm{Ag}$, and, its energy loss function $\operatorname{Im}\left(\frac{-1}{\varepsilon}\right)$, wherein $\varepsilon$ is the dielectric function of the material, offers no maxima of dielectric loss in the range from UV to VIS, thus making $\mathrm{Al}$ an excellent Drude metal in this range [24-27]. In terms of the optical absorption, the absorption 
efficiency of $\mathrm{Al}$ nanoparticles is greater than that of $\mathrm{Au}$ and $\mathrm{Ag}$, and is slightly smaller than that of alkali metals [28]. Therefore, plasmonic resonance of Al nanoantennas can be flexibly tuned over the UV-VIS to the IR region, just by adopting suitable nanostructured architectures [29-34].

In the past decades, plasmon-enhanced vibrational spectroscopic sensing including surface-enhanced Raman scattering (SERS) [35,36] and surface-enhanced infrared absorption spectroscopy (SEIRA) [37-39] have showed great advantage over the conventional spectroscopic methods in the trace molecular detection, especially for monolayer and single molecule via specific surface chemical functionalization [40-45]. In the field of SERS, many plasmonic antennas have been proposed for SERS substrates including plasmonic nanospheres $[40,46]$, nanorods $[47,48]$, nanotriangles $[17,49]$, particularly the structures having narrow gaps such as aggregate nanoparticles [50], nanoparticle dimers [46,51], nanoclusters [51,52], and nano-bowties [22,53,54]. Among them, plasmonic nano-bowties have attracted much attention because of its largest nearfield enhancement that could be achieved at the nanogaps between the two triangles [22,53]. On the other hand, the Raman cross section is increased in the short wavelength $(\lambda)$ region (UV-NIR) as a function of $\lambda^{-4}$, however, engineering the resonance of bowtie antennas in the UV-NIR region using $\mathrm{Au}$ and $\mathrm{Ag}$ is impossible due to their small plasma frequencies and the fabrication limit. Therefore, utilizing plasmonic $\mathrm{Al}$ for nanobowtie antennas can realize short-wavelength resonant antennas (500 nm-700 nm) for SERS applications.

In this letter, we numerically and experimentally demonstrated free-standing Al bowtie antennas for SERS study. As the group velocity of the "slow light" formed by the coupling of plasmon and light is screened by the dielectric property of the surrounding media, thus, having an equality of the group velocity by a homogeneous surrounded dielectric medium between the upper and lower metal/dielectric interfaces would give a better homogeneity of the distribution of the electromagnetic field [54]. Compared to the previous Al bowtie antennas for SERS that the Al bowties was placed directly on a fused silica substrate [22], in this work, by introducing a $\mathrm{SiO}_{2}$ post under each $\mathrm{Al}$ triangle, the nanogap area becomes free from the dielectric screening and thus the induced field enhancement at the nanogaps located between two plasmonic $\mathrm{Al}$ triangles could be increased and occupy a larger available volume for accommodating analyte molecules. We investigated the dark-field scattering mapping spectra of the plasmonic free-standing Al bowtie antennas, for correlating the obtained resonance with their sensing capability by the surface-enhanced Raman spectroscopy (SERS) of organic molecules. Supported by the numerical simulations, we showed that the free-standing Al bowtie arrays could be a powerful antenna platform for SERS. Our result also paves a way for the possible applications of the oxide-coated Al bowtie array serving as strong near-field optical antennas for SERS as well as other plasmon-enhanced spectroscopic devices.

\section{Materials and Methods}

The free-standing Al bowtie nanoantennas were fabricated by a standard procedure using electron beam (EB) lithography, lift-off, and reactive-ion etching (RIE) processes (Figure 1a). Prior to the fabrication, a 200-nm-thick layer of $\mathrm{SiO}_{2}$ was prepared by the thermal oxidation of a $1 \times 1 \mathrm{~cm}^{2} \mathrm{Si}$ wafer. An EB resist mask was prepared on a $200-\mathrm{nm}-\mathrm{SiO}_{2} / \mathrm{Si}$ substrate using an EB writer (Elionix, ESL-7500DEX, Tokyo, Japan). A 40-nmthick of Al with a 4-nm-adhesive $\mathrm{Cr}$ layer was then deposited on the substrate with the EB resist mask using EB deposition (UEP-300-2C, ULVAC, Kanagawa, Japan). After the lift-off step, an RIE process (ULVAC CE-300I, Kanagawa, Japan) with a mixture of $\mathrm{CHF}_{3} / \mathrm{O}_{2}$ (15-sccm/2.5-sccm) gases was applied to etch a 180-nmdepth $\mathrm{SiO}_{2}$ layer with $\mathrm{Al}$ bowties as mask, forming a 180-nm height $\mathrm{SiO}_{2}$ post underneath each $\mathrm{Al}$ triangle. The morphology of the fabricated Al bowtie arrays was characterized by using a field-emission scanning electron microscope (FE-SEM, Hitachi SU8000, Tokyo, Japan).

A con-focal Raman microscope (WITec Alpha 300S, Ulm, Germany) combined with a halogen lamp (Lucir-LAHL100) in UV-NIR range and a second harmonic diode pumped Nd:YAG laser (WITec, Ulm, Germany) at $532 \mathrm{~nm}$ was used for the investigation of the plasmonic scattering property (dark-field 
geometry, see Figure 1b) and the demonstration of the SERS effect (Figure 1c). As for the dark-field scattering measurements, a scanning mode equipped with a 50× dark-field lens (Zeiss, Oberkochen, Germany) was used. The relative scattering spectra were obtained by subtracting the spectra taken from the free-standing Al bowtie antennas with posts supported by the Si substrate to the spectra taken from a bare Si sample.

(a)

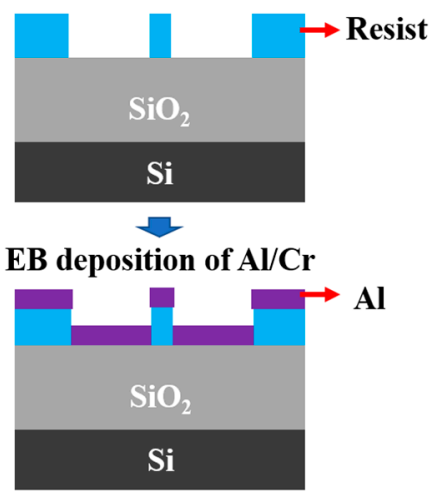

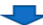

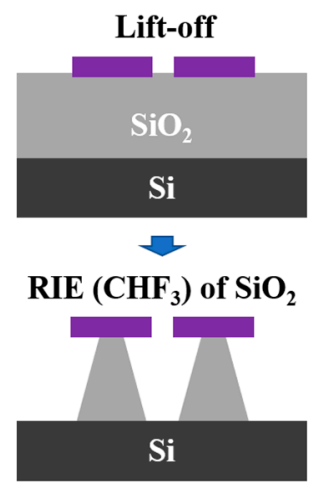

(b)

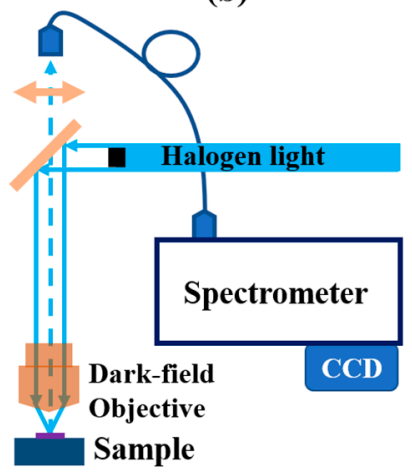

(c)

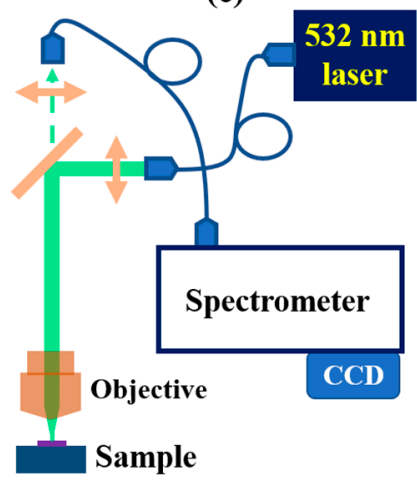

Figure 1. (a) Schematic illustration of the fabrication process. Optical microscopy setup of (b) dark-field measurement and (c) Raman measurement.

To demonstrate the SERS effect, a $10 \mu \mathrm{L}$ droplet of Nile-blue solution (concentration $3 \mu \mathrm{M}$ ) was spread over the $\mathrm{Al}$ bowtie arrays $\left(1 \times 1 \mathrm{~cm}^{2}\right.$ substrate $)$ and then dried in ambient condition. The SERS mapping measurements were performed on an area of $10 \mu \mathrm{m} \times 10 \mu \mathrm{m}$, with a spatial resolution of 40 pixel (250 nm/pixel), an integration time of $0.2 \mathrm{~s} /$ pixel. A $100 \times$ objective lens was used with an optimal laser power of $500 \mu \mathrm{W}$.

The rigorous coupled-wave analysis (RCWA) (DiffractMOD, Synopsys' RSoft, Version 2017.09, Ossining, NY, USA) and the finite-difference time-domain (FDTD) methods (FullWAVE, Synopsys'RSoft, Version 2017.09, Ossining, NY, USA) were employed to get further understanding on the optical properties of the plasmonic Al bowties as well as the enhancement nature of the electromagnetic field at their gaps and surfaces. The dielectric functions of $\mathrm{Al}, \mathrm{Cr}, \mathrm{Si}$ and $\mathrm{SiO}_{2}$ were referred from the literature [55,56]. The model of the free-standing Al bowtie structures used for the simulations was constructed based on a build-in CAD layout (RSoft CAD Environment ${ }^{\mathrm{TM}}$, Version 2017.09, Ossining, NY, USA). Each free-standing bowtie antenna composed of a Si substrate and two $\mathrm{SiO}_{2}$ posts (height of $180 \mathrm{~nm}$ ) and $\mathrm{Al}$ bowties. The Al bowties have the triangle shapes (length of $105 \mathrm{~nm}$, thickness of $40 \mathrm{~nm}$ ), and composed of a 4-nmthick native $\mathrm{Al}_{2} \mathrm{O}_{3}$ oxide layer on top and 4-nm-thick $\mathrm{Cr}$ adhesive layer underneath. To mimic the real structures, the triangular truncations were placed at the corners of the triangles. The periodic boundary and grid size conditions were optimized to simulate the whole structure. 


\section{Results}

Figure 2a presents the tilted-view FE-SEM image of an Al bowtie antenna array with parameters of $105 \mathrm{~nm}$ length, $20 \mathrm{~nm}$ gap, $1400 \mathrm{~nm}$ periodicity (the distance between two bowties), and $1120 \mathrm{~nm}$ spacing (the distance between two bowtie lines). The inset of Figure 2a shows a bowtie antenna standing freely on the $\mathrm{SiO}_{2}$ posts. The spectroscopic measurements of the $\mathrm{Al}$ bowtie antennas are presented in Figure $2 b, c$. As the obtained spectra are achieved by subtracting the dark-field scattering spectrum taken from the area with the presence of bowtie antennas with respect to the reference area of the bare $S i$ sample, it is hence inferred that our measurement reflects the plasmonic characteristics in the far-field of the antenna resonances. Under the near-field measurement, in the particular case of bowtie antennas, the resonance spectrum depends on the excited position of each single object. For example, the bowtie gap-mode (bright-mode) and dark-mode are seen under the excitation at the point near the gap, and at the point located far from the gap, respectively [57]. In the far-field measurement, the resonance spectrum is a superimposition of the scattering, emission, and interaction from the objects. There exists a difference between the near-field and far-field resonance. The far-field measurement reflects the resonant nature (the polarization is perpendicular or parallel to the bowtie axis) of the plasmonic nanoantennas and does not influence much on the SERS effect. In contrast, the near-field resonance does affect the SERS signals [58]. As seen in Figure 2b, the dark-field scattering spectral mapping of plasmonic resonance from the Al bowtie antenna array (taken in a range from $500 \mathrm{~nm}-700 \mathrm{~nm}$ of the resonance peak) indicates the far-field resonance of the antenna array, which reveals a clear spatial distribution of the circular spots following the periodicity of the actual antenna array.
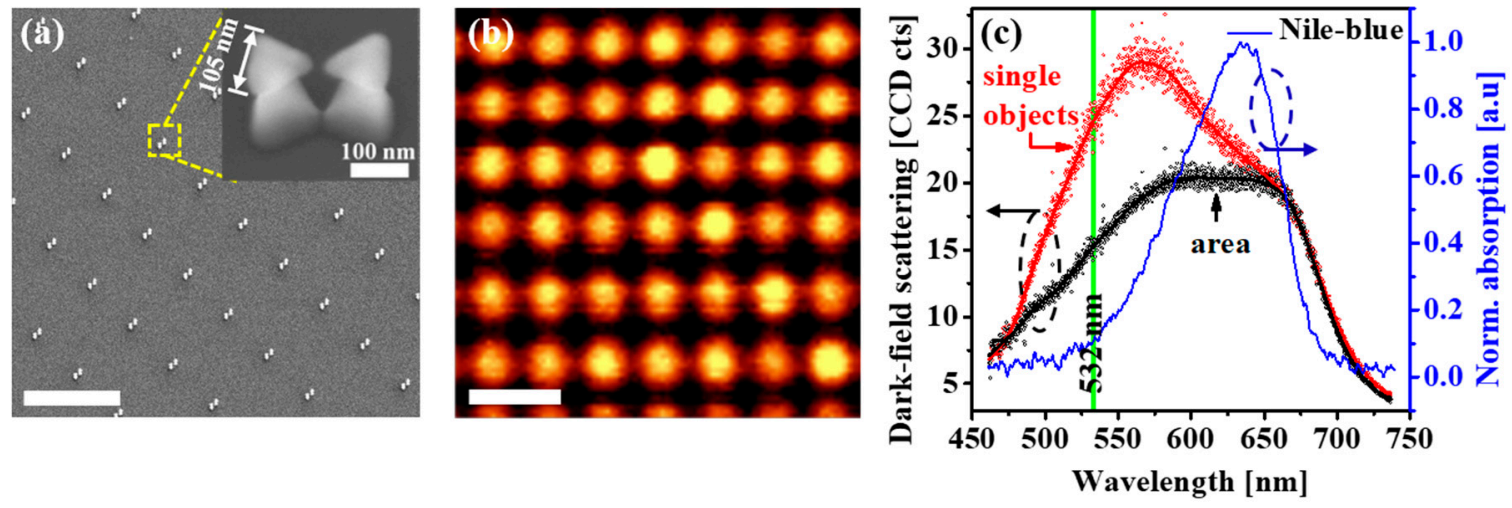

Figure 2. Spectral mapping of the free-standing Al bowtie antennas. (a) A scanning electron microscope (SEM) of the $\mathrm{Al}$ antenna arrays, observed at $30^{\circ}$ oblique angle and the inset of one typical bowtie antenna. The antennas are spatially distributed with periodicity of $1400 \mathrm{~nm}$, spacing of $1120 \mathrm{~nm}, 105 \mathrm{~nm}$ length and $20 \mathrm{~nm}$ gap. (b) The spectral mapping integrated over the resonance of the antennas, ranging from $500 \mathrm{~nm}$ to $700 \mathrm{~nm}$. The circular "hot-spots" are spatially distributed following the SEM image, as shown in (a). The scale bar is $2 \mu \mathrm{m}$ for both (a) and (b). (c) Spectral response of the single antenna (red), antenna array (black) and absorption spectrum of Nile-blue (blue), details in the text.

A comparison of the spectral characteristic between the single antenna and a scanned antenna array is shown in Figure 2c, together with the absorption spectrum of the organic Nile-blue solution, which was intentionally used as the probe molecules to demonstrate the field enhancement thanks to the SERS effect. The normalized dark-field scattering spectrum of the single objects shows a prominent plasmonic peak located at around $\sim 565 \mathrm{~nm}$ and a noticeable hump at $\sim 675 \mathrm{~nm}$, toward the longer wavelength region. In the spectrum averaged from an antenna array consisting of the individual objects, the interaction between them and the surrounding areas, it is obvious that the low energy (long wavelength) peak still remained, but the main resonance peak is no more dominant. 
Figure 3 shows the SERS measurements of the free-standing Al bowtie antennas with Nile-blue molecules. Very different from Au and Ag surfaces, which allow for achieving a well-defined chemical adsorption of a single layer of probe molecules (octadecanethiol (ODT), for instance), giving a precise estimation of the electromagnetic enhancement factor of the plasmonic nanoantennas [39]; the $\mathrm{Al}$ antennas are naturally coated by a few nanometer-thick $\mathrm{Al}_{2} \mathrm{O}_{3}$ that protects the $\mathrm{Al}$ surface from directly contacting the probe molecules. However, the $\mathrm{Al}_{2} \mathrm{O}_{3}$ is a fairly inert and reusable surface making it a promising SERS template for practical applications. The use of the $\mathrm{Al}_{2} \mathrm{O}_{3} / \mathrm{Al}$ configuration for the SERS measurements can solely demonstrate the electromagnetic field enhancement effect on SERS without any influence of the charge transfer (also known as chemical effect) between the plasmonic antennas and the Nile-blue molecules. The SERS performance of the free-standing Al bowtie arrays was investigated by evaluating the enhancement of the Raman spectrum of Nile-blue molecules. Figure 3a-c show an optical image (seen by confocal microscope), a reconstructed Raman mapping image (integrated at $590 \mathrm{~cm}^{-1}$ band), and a dark-field scattering mapping image of the corresponding area, respectively. Figure 3d presents the SERS spectra of Nile-blue molecules at the position "ON" the Al bowtie (red spectrum) and at the position "OFF" the Al bowtie (black spectrum). It is obvious that the Raman signals of Nile-blue fingerprints are strongly enhanced if the molecules are located at the position of $\mathrm{Al}$ bowties, giving clear evidence of the promising SERS effect due to the strong nearfield enhancement at the small gaps of the free-standing Al bowtie antennas. Additionally, the measurement of the polarization-dependent SERS was performed by using a half-wave plate to change the polarization of the excitation laser. The inset in Figure $3 \mathrm{~d}$ shows that the relative intensity of Raman signals at the $590 \mathrm{~cm}^{-1}$ peak in the case of the excitation laser with polarization parallel to the bowtie axis (red curve) is significantly higher than that of the perpendicular polarization excitation (black curve). As the Nile-blue molecules cover the bowtie antennas entirely, the overwhelming Raman signal of parallel polarization compared to the perpendicular polarization excitation reflects that the gap-mode (excited under parallel polarization) gives a larger enhancement than the quadrupolar mode (excited under perpendicular polarization), which is in agreement with the previous report [59].

(a) Optical image

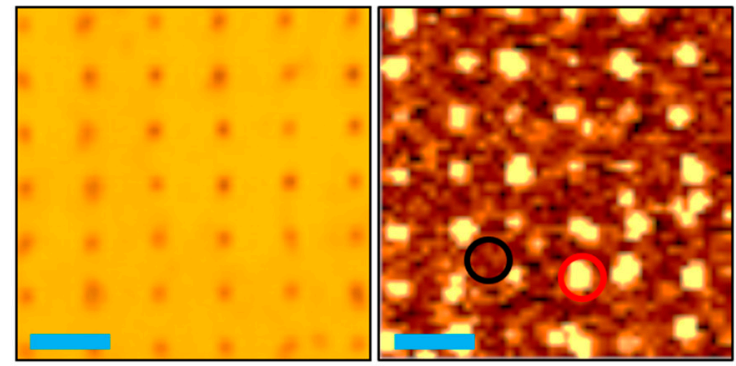

Figure 3. Cont. (c) Darkfield mapping

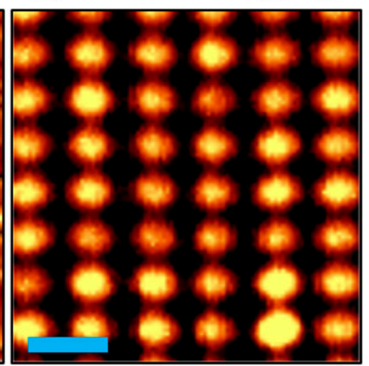




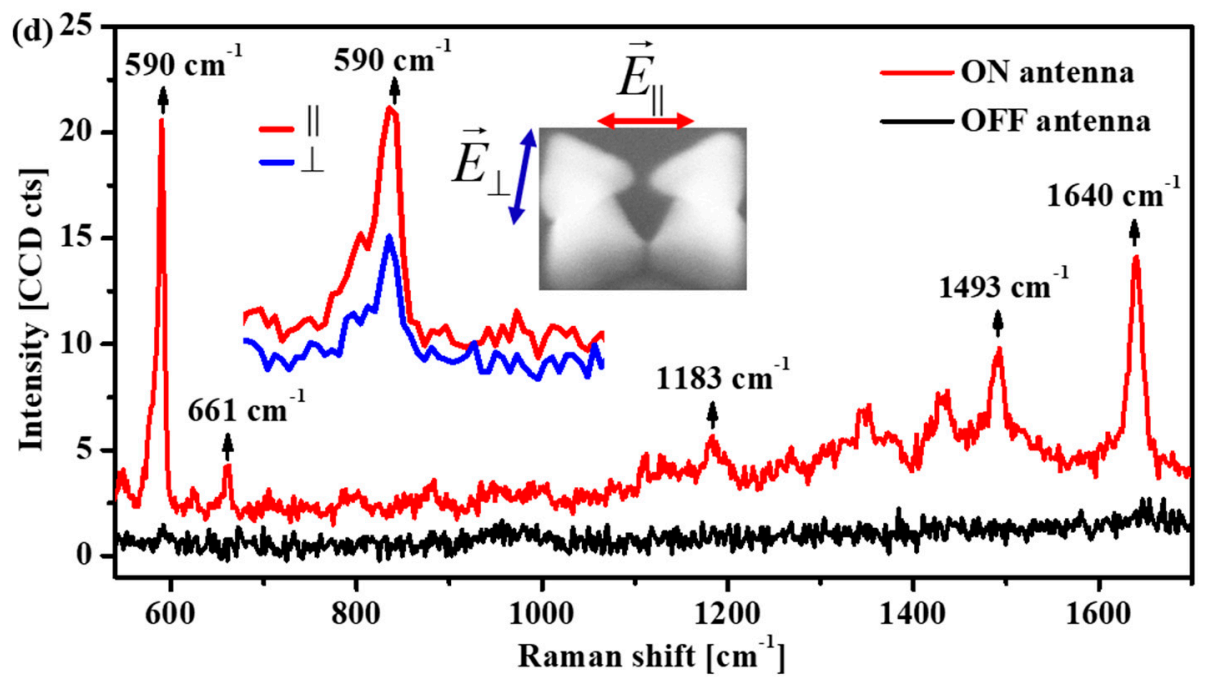

Figure 3. Demonstration of the electromagnetic field enhancement of free-standing bowtie antennas by SERS. (a) Optical image (seen under confocal microscope), (b) Raman mapping, and (c) corresponding plasmonic dark-field scattering mapping of the antenna arrays, respectively. The scale bar indicates 2 $\mu \mathrm{m}$ in all (a), (b), and (c). (d) SERS measurements of the Nile-blue molecules on the Al bowtie antennas. The black curve and red curve show Raman signals "OFF" and "ON" the antennas. The small inset indicates the Raman signals under different excitation conditions; with polarization parallel to the bowtie axis (red) and perpendicular to the bowtie axis (black), respectively.

The plasmonic resonance of the $\mathrm{Al}$ free-standing bowtie antennas was further elucidated using the numerical electromagnetic simulations; details are described in the Materials and Methods Section. Figure 4a shows the simulated extinction spectra of the floating $\mathrm{Al}$ bowtie antennas under two incident electric field polarizations; parallel to the bowtie axis with different gap sizes of $10 \mathrm{~nm}, 20 \mathrm{~nm}, 30 \mathrm{~nm}$ (solid curves), and perpendicular to the bowtie axis with agap of $10 \mathrm{~nm}$ (dashed curve), separately. When the incident electric field oscillates parallel to the bowtie axis, the extinction spectrum for a 10-nm-gap antenna array shows a clear single resonance at $540 \mathrm{~nm}$, and it is blue-shifted when the gap size increases. On the other hand, when the incident electric field oscillates perpendicular to the bowtie axis, the extinction spectrum of a 10-nm-gap bowtie antenna array tends to shift the resonance to the shorter wavelength region (see the dashed curve in Figure 4a). In comparison to the extinction spectrum measured on a single bowtie presented in Figure 2c, the simulated spectrum indicates a single peak, located closely to the main measured peak $(560 \mathrm{~nm})$. However, the simulation could not retrieve the second-(hump-like) peak at 670-nm. This discrepancy could be assigned to the fact that the free-standing architecture of the bowtie antennas results in a relatively strong far-field interaction, which could be seen only by far-field scattering experiments, not in the nearfield simulations [58]. Figure $4 \mathrm{~b}$ shows the electric field distribution of Al bowtie antennas under the excitation of 532nm with the incident electric field polarized perpendicular to the bowtie axis. In this case, the excited hot-spots are located at the corners of each triangles and the field enhancement was found to be about $E_{\mathrm{x}} / E_{\mathrm{x} 0}$ $=7$, where $E_{\mathrm{x}}$ and $E_{\mathrm{x} 0}$ are the amplitudes of the enhanced and incident electric fields, respectively. Figure $4 \mathrm{c}$, d show the electric field distribution of the Al bowtie antennas array with the incident electric field polarized parallel to the bowtie axis, under the same wavelength excitation of $532 \mathrm{~nm}$; side-view (Figure $4 \mathrm{c}$ ) and top-view (Figure $4 \mathrm{~d}$ ). It has been previously shown that the electric field enhancement decreases as the gap size of the bowtie increases [53,54]. As shown in Figure 4c,d, the electric field is mainly concentrated at the nanogap of the bowtie antennas. The enhanced area is homogeneously distributed over the gap and the enhancement factor $\left(E_{\mathrm{f}}\right)$ is calculated to be about $\left|E_{\mathrm{x}} / E_{\mathrm{x} 0}\right|=58$, which is much large rcompared to that of the perpendicular polarization excitation. It is consistent with the SERS results as discussed above where the SERS signal intensity under the electric field polarized 
parallel to the bowtie axis is stronger than that of the electric field polarized perpendicular to the bowtie axis (Figure $4 \mathrm{~d}$ ).
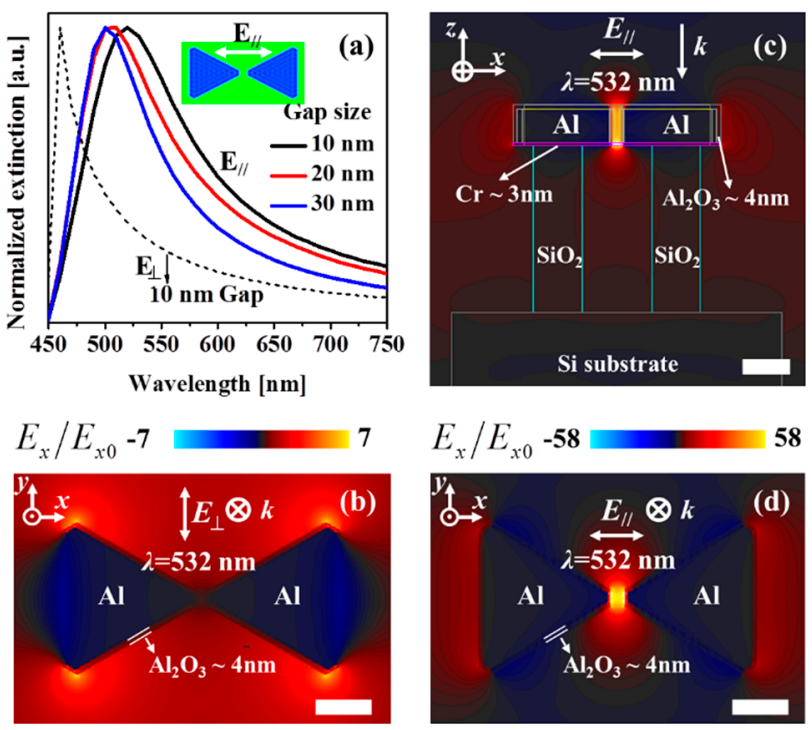

Figure 4. Simulated optical response and electric field distributions around Al bowtie excited at $532 \mathrm{~nm}$ wavelength. (a) Extinction spectra of the Al bowtie antennas at two different polarization conditions: parallel to the bowtie axis with different gap size of $10 \mathrm{~nm}, 20 \mathrm{~nm}, 30 \mathrm{~nm}$ (solid curves), and perpendicular to the bowtie axis with a $10 \mathrm{~nm}$ gap (dashed curve). The electric field distributions around a 105-nm-length, 10-nm-gap Al bowtie array excited at the 532-nm wavelength are simulated with two polarized excitations: (b) Perpendicular polarization, (c) and (d) parallel polarization with side-view and top-view, respectively. The scale bar is $50 \mathrm{~nm}$ for all panels (b), (c) and (d). The electric field hot-spot shows a strong electric field confinement with an enhancement factor $\left|E_{\mathrm{x}} / E_{\mathrm{x} 0}\right|$ of 58 , where $E_{\mathrm{x}}$ and $E_{\mathrm{x} 0}$ are the amplitudes of the enhanced and incident electric fields, respectively.

\section{Conclusions}

In summary, we have numerically and experimentally demonstrated short-wavelength plasmonic Al bowtie antennas for SERS application at the 532-nm excitation. The free-standing Al bowtie antennas exhibited a strong electric field enhancement as high as 58 when excited at the $532 \mathrm{~nm}$. We also further investigated optical properties of the fabricated free-standing Al bowtie antennas by introducing a plasmonic dark-field scattering mapping, which revealed the resonance of each individual antenna in the range between $500 \mathrm{~nm}-675 \mathrm{~nm}$. Despite of having a natural oxide $\mathrm{Al}_{2} \mathrm{O}_{3}$ layer, and the absence of the chemical SERS effect, the correlated SERS mapping of Nile-blue molecules on Al bowties excited by a 532-nm laser clearly showed that the SERS signals were observed only at the bowtie antenna position. This evidences that the free-standing Al bowties exhibited a high SERS performance owing to the strongly confined electromagnetic field at the nanogaps between each triangle-pair of the bowtie antennas. Together with a recently proposed surface functionalization method of Al nanoantennas by using phosphoric acid [34], this work puts another step towards the practical applications of aluminum nano antennas in plasmonic sensing as well as in plasmon-enhanced nanospectroscopy.

Author Contributions: T.D.D. and C.V.H. performed the numerical simulations. A.O. and T.N. (Toshihide Nabatame) fabricated devices. C.V.H., T.D.D. conducted the spectroscopic measurements, characterized data. C.V.H., T.D.D. and T.N. (Tadaaki Nagao) co-wrote the manuscript with inputs from N.N. and N.Y. M.A. contributed to the discussions. T.N. (Tadaaki Nagao) supervised the project.

Acknowledgments: This work was partially supported by a Grant-in-Aid for Scientific Research (KAKENHI) projects (16F16315, JP16H06364, 16H03820) from the Japan Society for the Promotion of Science (JSPS), World Premier International Research Center Initiative on "Materials NanoArchitectonics" from MEXT (Japan) and CREST "Phase Interface Science for Highly Efficient Energy Utilization" (JPMJCR13C3) from Japan Science and 
Technology Agency. C.V.H acknowledges the financial support from the Vietnam Academy of Science and Technology under the project VAST03.07/19-20.

Conflicts of Interest: The authors declare no conflict of interest.

\section{References}

1. Cortie, M.B.; Giddings, J.; Dowd, A. Optical properties and plasmon resonances of titanium nitride nanostructures. Nanotechnology 2010, 21, 115201. [CrossRef] [PubMed]

2. Naik, G.V.; Shalaev, V.M.; Boltasseva, A. Alternative Plasmonic Materials: Beyond Gold and Silver. Adv. Mater. 2013, 25, 3264-3294. [CrossRef] [PubMed]

3. Li, W.; Guler, U.; Kinsey, N.; Naik, G.V.; Boltasseva, A.; Guan, J.; Shalaev, V.M.; Kildishev, A.V. Refractory Plasmonics with Titanium Nitride: Broadband Metamaterial Absorber. Adv. Mater. 2014, 26, 7959-7965. [CrossRef] [PubMed]

4. Kumar, M.; Umezawa, N.; Ishii, S.; Nagao, T. Examining the Performance of Refractory Conductive Ceramics as Plasmonic Materials: A Theoretical Approach. ACS Photonics 2016, 3, 43-50. [CrossRef]

5. Dionne, J.A.; Sweatlock, L.A.; Sheldon, M.T.; Alivisatos, A.P.; Atwater, H.A. Silicon-Based Plasmonics for On-Chip Photonics. IEEE J. Sel. Top. Quantum Electron. 2010, 16, 295-306. [CrossRef]

6. Robusto, P.F.; Braunstein, R. Optical Measurements of the Surface Plasmon of Indium-Tin Oxide. Phys. Status Solidi A 1990, 119, 155-168. [CrossRef]

7. Ginn, J.C.; Jarecki, R.L.; Shaner, E.A.; Davids, P.S. Infrared plasmons on heavily-doped silicon. J. Appl. Phys. 2011, 110, 043110. [CrossRef]

8. Kanehara, M.; Koike, H.; Yoshinaga, T.; Teranishi, T. Indium Tin Oxide Nanoparticles with Compositionally Tunable Surface Plasmon Resonance Frequencies in the Near-IR Region. J. Am. Chem. Soc. 2009, 131, 17736-17737. [CrossRef]

9. Chen, K.; Guo, P.; Dao, T.D.; Li, S.; Ishiii, S.; Nagao, T.; Chang, R.P. Protein-Functionalized Indium-Tin Oxide Nanoantenna Arrays for Selective Infrared Biosensing. Adv. Opt. Mater. 2017, 5, 1700091. [CrossRef]

10. Jablan, M.; Buljan, H.; Soljačić, M. Plasmonics in graphene at infrared frequencies. Phys. Rev. B 2009, 80, 245435. [CrossRef]

11. Grigorenko, A.N.; Polini, M.; Novoselov, K.S. Graphene plasmonics. Nat. Photonics 2012, 6, 749. [CrossRef]

12. Ni, G.X.; Wang, L.; Goldflam, M.D.; Wagner, M.; Fei, Z.; McLeod, A.S.; Liu, M.K.; Keilmann, F.; Özyilmaz, B.; Castro Neto, A.H.; et al. Ultrafast optical switching of infrared plasmonpolaritons in high-mobility graphene. Nat. Photonics 2016, 10, 244. [CrossRef]

13. Lundeberg, M.B.; Gao, Y.; Asgari, R.; Tan, C.; Van Duppen, B.; Autore, M.; Alonso-González, P.; Woessner, A.; Watanabe, K.; Taniguchi, T.; et al. Tuning quantum nonlocal effects in graphene plasmonics. Science 2017, 357, 187-191. [CrossRef] [PubMed]

14. AlcarazIranzo, D.; Nanot, S.; Dias, E.J.C.; Epstein, I.; Peng, C.; Efetov, D.K.; Lundeberg, M.B.; Parret, R.; Osmond, J.; Hong, J.-Y.; et al. Probing the ultimate plasmon confinement limits with a van der Waals heterostructure. Science 2018, 360, 291-295. [CrossRef] [PubMed]

15. Ni, G.X.; McLeod, A.S.; Sun, Z.; Wang, L.; Xiong, L.; Post, K.W.; Sunku, S.S.; Jiang, B.-Y.; Hone, J.; Dean, C.R.; et al. Fundamental limits to graphene plasmonics. Nature 2018, 557, 530-533. [CrossRef] [PubMed]

16. Langhammer, C.; Schwind, M.; Kasemo, B.; Zorić, I. Localized Surface Plasmon Resonances in Aluminum Nanodisks. Nano Lett. 2008, 8, 1461-1471. [CrossRef]

17. Chan, G.H.; Zhao, J.; Schatz, G.C.; Van Duyne, R.P. Localized Surface Plasmon Resonance Spectroscopy of Triangular Aluminum Nanoparticles. J. Phys. Chem. C 2008, 112, 13958-13963. [CrossRef]

18. Knight, M.W.; Liu, L.; Wang, Y.; Brown, L.; Mukherjee, S.; King, N.S.; Everitt, H.O.; Nordlander, P.; Halas, N.J. Aluminum PlasmonicNanoantennas. Nano Lett. 2012, 12, 6000-6004. [CrossRef]

19. Sigle, D.O.; Perkins, E.; Baumberg, J.J.; Mahajan, S. Reproducible Deep-UV SERRS on Aluminum Nanovoids. J. Phys. Chem. Lett. 2013, 4, 1449-1452. [CrossRef]

20. West, P.R.; Ishii, S.; Naik, G.V.; Emani, N.K.; Shalaev, V.M.; Boltasseva, A. Searching for better plasmonic materials. Laser Photonics Rev. 2010, 4, 795-808. [CrossRef]

21. Jha, S.K.; Ahmed, Z.; Agio, M.; Ekinci, Y.; Löffler, J.F. Deep-UV Surface-Enhanced Resonance Raman Scattering of Adenine on Aluminum Nanoparticle Arrays. J. Am. Chem. Soc. 2012, 134, 1966-1969. [CrossRef] 
22. Li, L.; Fang Lim, S.; Puretzky, A.A.; Riehn, R.; Hallen, H.D. Near-field enhanced ultraviolet resonance Raman spectroscopy using aluminum bow-tie nano-antenna. Appl. Phys. Lett. 2012, 101, 113116. [CrossRef]

23. Johnson, P.B.; Christy, R.W. Optical Constants of the Noble Metals. Phys. Rev. B 1972, 6, 4370-4379. [CrossRef]

24. Ehrenreich, H.; Philipp, H.R.; Segall, B. Optical Properties of Aluminum. Phys. Rev. 1963, 132, $1918-1928$. [CrossRef]

25. Batson, P.E.; Silcox, J. Experimental energy-loss function, $\operatorname{Im}[-1 \varepsilon(q, \omega)]$, for aluminum. Phys. Rev. B 1983, 27, 5224-5239. [CrossRef]

26. Lee, K.-H.; Chang, K.J. First-principles study of the optical properties and the dielectric response of Al. Phys. Rev. B 1994, 49, 2362-2367. [CrossRef]

27. Andersson, T.; Zhang, C.; Tchaplyguine, M.; Svensson, S.; Mårtensson, N.; Björneholm, O. The electronic structure of free aluminum clusters: Metallicity and plasmons. J. Chem. Phys. 2012, 136, 204504. [CrossRef] [PubMed]

28. Blaber, M.G.; Arnold, M.D.; Harris, N.; Ford, M.J.; Cortie, M.B. Plasmon absorption in nanospheres: A comparison of sodium, potassium, aluminium, silver and gold. Phys. B Condens. Matter 2007, 394, 184-187. [CrossRef]

29. Stöckli, T.; Bonard, J.-M.; Stadelmann, P.-A.; Châtelain, A. EELS investigation of plasmon excitations in aluminum nanospheres and carbon nanotubes. Z. Phys. D Atoms Mol. Clust. 1997, 40, 425-428.

30. Lehr, D.; Dietrich, K.; Helgert, C.; Käsebier, T.; Fuchs, H.-J.; Tünnermann, A.; Kley, E.-B. Plasmonic properties of aluminum nanorings generated by double patterning. Opt. Lett. 2012, 37, 157-159. [CrossRef]

31. Taguchi, A.; Saito, Y.; Watanabe, K.; Yijian, S.; Kawata, S. Tailoring plasmon resonances in the deep-ultraviolet by size-tunable fabrication of aluminum nanostructures. Appl. Phys. Lett. 2012, 101, 081110. [CrossRef]

32. Saito, Y.; Honda, M.; Watanabe, K.; Taguchi, A.; Song, Y.; Kawata, S. Design of Aluminum Nanostructures for DUV Plasmonics: Blue Shifts in Plasmon Resonance Wavelength by Height Control. J. Jpn. Inst. Met. 2013, 77, 27-31. [CrossRef]

33. Dao, T.D.; Chen, K.; Ishii, S.; Ohi, A.; Nabatame, T.; Kitajima, M.; Nagao, T. Infrared Perfect Absorbers Fabricated by Colloidal Mask Etching of $\mathrm{Al}-\mathrm{Al}_{2} \mathrm{O}_{3}-\mathrm{Al}$ Trilayers. ACS Photonics 2015, 2, 964-970. [CrossRef]

34. Chen, K.; Dao, T.D.; Ishii, S.; Aono, M.; Nagao, T. Infrared Aluminum Metamaterial Perfect Absorbers for Plasmon-Enhanced Infrared Spectroscopy. Adv. Funct. Mater. 2015, 25, 6637-6643. [CrossRef]

35. Fleischmann, M.; Hendra, P.J.; McQuillan, A.J. Raman spectra of pyridine adsorbed at a silver electrode. Chem. Phys. Lett. 1974, 26, 163-166. [CrossRef]

36. Jeanmaire, D.L.; Van Duyne, R.P. Surface Raman spectroelectrochemistry: Part I. Heterocyclic, aromatic, and aliphatic amines adsorbed on the anodized silver electrode. J. Electroanal. Chem. Interfacial Electrochem. 1977, 84, 1-20. [CrossRef]

37. Hartstein, A.; Kirtley, J.R.; Tsang, J.C. Enhancement of the Infrared Absorption from Molecular Monolayers with Thin Metal Overlayers. Phys. Rev. Lett. 1980, 45, 201-204. [CrossRef]

38. Nishikawa, Y.; Nagasawa, T.; Fujiwara, K.; Osawa, M. Silver island films for surface-enhanced infrared absorption spectroscopy: Effect of island morphology on the absorption enhancement. Vib. Spectrosc. 1993, 6, 43-53. [CrossRef]

39. Neubrech, F.; Pucci, A.; Cornelius, T.W.; Karim, S.; García-Etxarri, A.; Aizpurua, J. Resonant Plasmonic and Vibrational Coupling in a Tailored Nanoantenna for Infrared Detection. Phys. Rev. Lett. 2008, 101, 157403. [CrossRef]

40. Nie, S.; Emory, S.R. Probing Single Molecules and Single Nanoparticles by Surface-Enhanced Raman Scattering. Science 1997, 275, 1102-1106. [CrossRef]

41. Kneipp, K.; Kneipp, H.; Itzkan, I.; Dasari, R.R.; Feld, M.S. Surface-enhanced Raman scattering and biophysics. J. Phys. Condens. Matter 2002, 14, R597. [CrossRef]

42. Enders, D.; Nagao, T.; Nakayama, T.; Aono, M. In Situ Surface-Enhanced Infrared Absorption Spectroscopy for the Analysis of the Adsorption and Desorption Process of Au Nanoparticles on the $\mathrm{SiO}_{2} / \mathrm{Si}$ Surface. Langmuir 2007, 23, 6119-6125. [CrossRef] [PubMed]

43. Nagao, T.; Han, G.; Hoang, C.; Wi, J.-S.; Pucci, A.; Weber, D.; Neubrech, F.; Silkin, V.M.; Enders, D.; Saito, O; et al. Plasmons in nanoscale and atomic-scale systems. Sci. Technol. Adv. Mater. 2010, 11, 054506. [CrossRef] [PubMed] 
44. Enders, D.; Nagao, T.; Pucci, A.; Nakayama, T.; Aono, M. Surface-enhanced ATR-IR spectroscopy with interface-grown plasmonic gold-island films near the percolation threshold. Phys. Chem. Chem. Phys. 2011, 13, 4935-4941. [CrossRef] [PubMed]

45. Hoang, C.V.; Oyama, M.; Saito, O.; Aono, M.; Nagao, T. Monitoring the Presence of Ionic Mercury in Environmental Water by Plasmon-Enhanced Infrared Spectroscopy. Sci. Rep. 2013, 3, 1175. [CrossRef] [PubMed]

46. Talley, C.E.; Jackson, J.B.; Oubre, C.; Grady, N.K.; Hollars, C.W.; Lane, S.M.; Huser, T.R.; Nordlander, P.; Halas, N.J. Surface-Enhanced Raman Scattering from Individual Au Nanoparticles and Nanoparticle Dimer Substrates. Nano Lett. 2005, 5, 1569-1574. [CrossRef] [PubMed]

47. von Maltzahn, G.; Centrone, A.; Park, J.-H.; Ramanathan, R.; Sailor, M.J.; Hatton, T.A.; Bhatia, S.N. SERS-Coded Gold Nanorods as a Multifunctional Platform for Densely Multiplexed Near-Infrared Imaging and Photothermal Heating. Adv. Mater. 2009, 21, 3175-3180. [CrossRef]

48. Zhang, C.-L.; Lv, K.-P.; Huang, H.-T.; Cong, H.-P.; Yu, S.-H. Co-assembly of Au nanorods with Ag nanowires within polymer nanofiber matrix for enhanced SERS property by electrospinning. Nanoscale 2012, 4, 5348-5355. [CrossRef]

49. Haynes, C.L.; Van Duyne, R.P. Plasmon-Sampled Surface-Enhanced Raman Excitation Spectroscopy. J. Phys. Chem. B 2003, 107, 7426-7433. [CrossRef]

50. Jiang, J.; Bosnick, K.; Maillard, M.; Brus, L. Single Molecule Raman Spectroscopy at the Junctions of Large Ag Nanocrystals. J. Phys. Chem. B 2003, 107, 9964-9972. [CrossRef]

51. Lim, D.-K.; Jeon, K.-S.; Kim, H.M.; Nam, J.-M.; Suh, Y.D. Nanogap-engineerable Raman-active nanodumbbells for single-molecule detection. Nat. Mater. 2009, 9, 60. [CrossRef] [PubMed]

52. Ye, J.; Wen, F.; Sobhani, H.; Lassiter, J.B.; Van Dorpe, P.; Nordlander, P.; Halas, N.J. Plasmonic Nanoclusters: Near Field Properties of the Fano Resonance Interrogated with SERS. Nano Lett. 2012, 12, 1660-1667. [CrossRef] [PubMed]

53. Schuck, P.J.; Fromm, D.P.; Sundaramurthy, A.; Kino, G.S.; Moerner, W.E. Improving the Mismatch between Light and Nanoscale Objects with Gold Bowtie Nanoantennas. Phys. Rev. Lett. 2005, 94, 017402. [CrossRef] [PubMed]

54. Hatab, N.A.; Hsueh, C.-H.; Gaddis, A.L.; Retterer, S.T.; Li, J.-H.; Eres, G.; Zhang, Z.; Gu, B. Free-Standing Optical Gold Bowtie Nanoantenna with Variable Gap Size for Enhanced Raman Spectroscopy. Nano Lett. 2010, 10, 4952-4955. [CrossRef] [PubMed]

55. Rakić, A.D.; Djurišić, A.B.; Elazar, J.M.; Majewski, M.L. Optical properties of metallic films for vertical-cavity optoelectronic devices. Appl. Opt. 1998, 37, 5271-5283. [CrossRef] [PubMed]

56. Palik, E.D. Handbook of Optical Constants of Solids, 3rd ed.; Academic Press: New York, NY, USA, 1998.

57. Fung, K.H.; Kumar, A.; Fang, N.X. Electron-photon scattering mediated by localized plasmons: A quantitative analysis by eigen-response theory. Phys. Rev. B 2014, 89, 045408. [CrossRef]

58. Doherty, M.D.; Murphy, A.; Pollard, R.J.; Dawson, P. Surface-Enhanced Raman Scattering from Metallic Nanostructures: Bridging the Gap between the Near-Field and Far-Field Responses. Phys. Rev. X 2013, 3, 011001. [CrossRef]

59. Gómez-Medina, R.; Yamamoto, N.; Nakano, M.; García de Abajo, F.J. Mapping plasmons in nanoantennas via cathodoluminescence. New J. Phys. 2008, 10, 105009. [CrossRef]

(C) 2019 by the authors. Licensee MDPI, Basel, Switzerland. This article is an open access article distributed under the terms and conditions of the Creative Commons Attribution (CC BY) license (http://creativecommons.org/licenses/by/4.0/). 